\title{
Replacing the Annual Budget with Business Intelligence Driver-Based Forecasts
}

\author{
Lisa De Leon, Patricia D. Rafferty, Richard Herschel \\ Erivan K. Haub School of Business, Saint Joseph’s University, Philadelphia, USA \\ Email: patricia.rafferty@sju.edu
}

Received September 8, 2011; revised October 20, 2011; accepted October 28, 2011

\begin{abstract}
The fixed annual budget process can be a cumbersome and static process, often failing to deliver intended benefits. Typically detached from business operations and strategic planning goals, the annual budget suffers from inherent weaknesses caused by a lack of business intelligence regarding its underlying assumptions. This weakness is well documented in existing literature and there is ample evidence of improved alternatives to static corporate financial planning. One such alternative utilizes business intelligence as an essential component in the annual budget process, along with rolling forecasts as a critical tool. Utilizing business intelligence supported, driver-based rolling forecasting can align an organization's budget process with strategic objectives and can further the operational and financial strength of an organization, as well as maximize shareholder value. In order to fully explore this topic, this article will present a review of the conventional annual budget process and the manner in which an approach that bases financial forecasts on business intelligence drivers can align operations with strategic objectives and add value to an organization. An assessment of intelligence-supported, driver-based rolling forecasting will also be presented, demonstrating an improved approach to the traditional annual budgeting process.
\end{abstract}

Keywords: Business Intelligence; Budget; Forecast; Rolling Forecast; Driver-Based; Strategic Planning; Financial Planning

\section{Introduction}

The fixed annual budget process can be a cumbersome and static process, often failing to deliver its intended benefits. Typically detached from business operations and strategic planning goals, the fixed annual budget suffers from inherent weaknesses and fails to serve as an effective and dynamic business tool for many organizations. This is due to the manner in which the fixed annual budget remains unchanged and does not respond to variations in business activities [1]. Despite these limitations, many organizations continue to use the fixed annual budget as a performance forecast of revenues and expenses, while assuming a set of organizational targets, events, and operating plans. At the same time, fixed budgets serve as a guide for achieving these set organizational targets within a specific time period [2].

However, conditions frequently change during the normal course of a budget year and unanticipated risks and opportunities often arise that have a direct affect on the organizational targets defined in the operating plan. Unexpected risks often prevent an organization from achieving its set goals, while unpredicted opportunities can allow an organization to exceed its targets as long as there is time to leverage these prospects [3]. However, the fixed annual budget does not allow for the identification of new risks and opportunities due to its fixed and unchanging representation of the business plan at the time the budget is produced. This is problematic in a fluctuating and unpredictable economic environment. Instead, a more flexible, up-to-date, and responsive approach will allow for new risks and opportunities to be identified and empower an organization to respond effectively and efficiently [2].

Traditionally, the preparation of the annual budget was limited to spreadsheets, which often results in a disproportionate amount of time to be spent on budget creation and analysis [4]. However, advances in technology, analytics, and other planning tools allow for an improved approach to corporate financial planning than the traditional fixed budget process. For example, multicriteria decision analysis (MCDA) and rolling forecasts can replace the traditional, fixed annual budget process when utilized with well-implemented technology solutions. MCDA is a form of decision-tree analysis and modeling that factors uncertain events and outcomes in decision-making; however, it is not widely used in today's corporate planning arena [5]. Conversely, rolling fore- 
casts have become a widely acceptable method of planning and a valuable approach. A rolling forecast is a process of budget planning that removes historical periods to add future periods and iteratively compels an organization to focus on the future [6].

Some key factors to a well-implemented rolling forecast involve evaluating, understanding, and utilizing drivers as the basis of the forecast. However, arriving at the specific drivers necessary to implement robust, driverbased planning can be challenging given the large volume of data, the complexity of today's business operations, and the rapidly changing business environment [7]. To overcome these challenges, business intelligence methodologies can be employed to effectively and efficiently evaluate, understand, and apply the drivers necessary to create and maintain a flexible and accurate rolling budget forecast process [8].

In order to best understand the benefits of business intelligence driver-based rolling forecasting, it is important to better understand the limitations of the fixed annual budget process, the meaning of driver-based rolling forecasting, and the critical role business intelligence provides in establishing and maintaining the correct drivers. Using a dynamic enterprise model [3] as the conceptual framework for this topic, the following sections will expound on this subject and present three key topic areas.

\section{The Annual Budget, Rolling Forecasts, and Driver-Based Planning}

For many companies, the traditional annual budget remains the conventional management instrument; however, the process is often cumbersome and arduous, with few tangible rewards. As a result, the process often contradicts the cost-containing goals that most budgets hope to achieve by draining time and resources that may be better spent on the operational and strategic goals. This protracted and laborious process often causes delays, causing many budgets to remain unfinished at the start of the fiscal year [9].

Although these deficiencies are well documented, the traditional annual budget is still a part of financial planning for many organizations. The following section will further explore this topic.

\subsection{The Annual Budget}

Traditional budgeting is designed to be a process for creating a plan to guide an organization in achieving a prescribed level of performance. It is also used as a management tool for cost containment and assessing organizational and divisional management performance. As a cost containment tool, the budget is used to plan and track expenses associated with the operations of an organization [1].
However, the reliance on historical data and trends inherent in traditional fixed budgeting does not allow managers to have clear insight into what exactly drives the business. As a result, managers responsible for submitting their operational budgets often prepare budgets using conservative estimates or "pad" their budgets to off-set uncertainty or to compensate for unexpected expenses during the fiscal year. However, these excess funds may be better allocated if directed toward resourcing opportunities in other operational areas that may create incremental value [2].

Yet, many managers and budget planners lack the insight regarding what actually drives the business to plan more accurately. They often do not have the management tools to accurately predict and control for these factors, nor do they understand the complex variables that have an impact on disparate functional areas [10]. These shortcomings are exacerbated when managers set budgets for a fixed time period, often rendering the plan obsolete in the face of changing business conditions [2].

In addition to a cost containment instrument, the annual budget also serves as a performance measurement tool and is used to assess how well an operating manager is utilizing allotted resources. Actual revenue and expenses are compared to the set budget and, oftentimes, management incentive plans are tied to the manner in which a manager is able to adhere to their budget. As a result, managers seek to "come in under budget," yet another example for the motivation of managers to "pad" their budgets at the time of planning. Budget-based performance compensation is common and adds to the impediment to creating accurate budgets that provide a clear picture of what it will take to achieve the strategic objectives of an organization [2].

Under these circumstances, the annual budget fails to provide executive leadership with an accurate picture of what will drive and achieve strategic objectives and this type of budgetary scenario often fails to provide a CEO with proper insight into what is driving revenue and expenses. Therefore budget cuts are often done randomly, undermining high-performing business units while sustaining underperforming ones. These "across-the-board" budget cuts are indicative of an organization that lacks insight and intelligence into its business [10].

Perhaps the most distressing consequence of a budgetary approach lacking a foundation in operational business drivers is the tendency for managers to spend every last dollar left in their budgets at the end of the fiscal year for fear of losing dollars in the subsequent year. As a result, strategically oriented cost containment is surrendered, while strategic resource allocation is compromised [7].

Another challenge with the traditional annual budget is its reliance on the use of spreadsheets as one of the primary process tools. Whether an organization uses a top- 
down, bottom-up, or iterative budgeting process, there is often an inability for cross-operational planning due to the lack of a connected budgetary plan [11]. Moreover, the existence of numerous, disparate spreadsheets contribute to the protracted, and often delayed, budgetary process [12]. However with the advances in technology and analytic tools, finance professionals now have the ability to forego outmoded spreadsheets and streamline budgeting, planning, and forecasting across the organization [4].

These improved approaches illustrate there are more effective and efficient alternatives to the use of disconnected spreadsheets and the static budget process. The following section will explore a budget model that offers a more flexible and dynamic approach.

\subsection{Rolling Forecasts}

One alternative to the traditional annual budget is the concept of the rolling forecast. This approach differs from the traditional fixed budget and static forecast in that it eliminates the constraints of a set forecast period with a defined and unchanging end point. This rolling approach allows for the forecasted periods to remain the same, regardless of the accounting close. As one month or quarter closes, it is simply dropped from the forecast and a new month or quarter is added to the end of the forecasted scope. The rolling forecast end period is constantly projected forward [7].

The rolling forecast process compels managers to review business operations more frequently and strategically than is required in a fixed annual budget process [2]. Instead of looking at historical budget data, the rolling forecast necessitates managers to look forward and adjust their plans to achieve strategic targets and react to changing business conditions, enabling them to take immediate action if performance gaps occur or new business opportunities arise [9].

With this type of approach, the rolling forecast becomes a strategic tool and, in order to maximize utility, the process should begin with the strategic plan of the organization. In this way, the rolling forecast is system-supported and flexible, ensuring the overall organizational strategy is aligned with the operating units. This promotes fiscal and strategic interdependencies, as well as flexible recourse allocation for the organization. With this approach, rolling forecast frequency is not only dependent on the nature of the business, but is also rooted in the following goals: 1 ) reducing the budget preparation time, allowing for contingency analysis and planning, 3) minimizing unnecessary detail and 4) maximizing resource utilization within a systems framework [10].

In order for achieve these multiple objectives with a rolling forecast approach; it is necessary to utilize driverbased planning. The following section will explore this topic and how driver-based planning is implemented within a rolling forecast context.

\subsection{Driver-Based Planning}

The use of driver-based planning is a budgetary approach designed to directly affect managerial decision-making [13]. The objective is to focus the planning process on those activities that drive business performance and focus on variables that can be controlled [14]. This allows managers to develop a more accurate picture of future organizational performance by the deliberate and purposeful management of the key operational activities that drive these results [15].

Driver-based planning is rooted in the concept of modeling and that budgetary line items within a plan have an intrinsic blueprint that forms the basis of linking activity drivers to financial relationships [15]. The concept is especially useful for items that vary in cost and change with volume. An example of a budgetary line that can be used in driver-based planning is variable labor expenses, which is typically forecasted using number of hours worked and an hourly salary rate. By using the driver, hourly salary rate, a manager can plan for total variable labor expenses by utilizing the forecasted variable labor hours. If projected variable labor hours change, the total variable labor expenses can be quickly updated by replacing the old units with new units and applying the hourly rate. This simple illustration demonstrates the significant benefits of a driver-based planning process in rapidly updating more complex forecasts [16].

Additional benefits to driver-based planning involve time and cost savings, more accurate projections on future performance, scenario analysis, and the ability to perform cause-and-effect analysis. For example, using drivers to produce forecasts generates time and cost savings by enabling managers to simply review and update their budgetary units or rates to produce a new forecast. This represents a significant time and cost savings over the traditional budgeting process, which entails reviewing every single budget line item [15].

Similarly, cause and effect relationships are more easily identified when utilizing driver-based planning. This facilitates managerial decision making with regard to defining those variables that caused missed projections and taking corrective action. The ability to identify cause and effect relationships also allow managers to take advantage of unexpected opportunities and make operational modifications that will maximize these opportunities [17].

Driver-based planning also allows for the use of predictive modeling, or "what-if" scenarios [18]. Managers can more easily evaluate various units and rates when preparing their forecasts, enabling them to see how one 
decision may be better than another. This is particularly useful when there is a high degree of uncertainty and projections have a significant impact on strategic objecttives [16]. Furthermore, the use of "what-if" scenarios in driver-based planning can also provide utility when dealing with forecasts that project far into the future. This method becomes ideal for indentifying patterns and trends in performance, rather than a method for providing precise numbers and data [18].

Finally, and perhaps most importantly, driver-based planning allows managerial decision making to be linked to the strategic objects of the organization [8]. This approach connects the strategic targets of the business to its operating plan and creates a feedback mechanism between various operating units. When the input from the operations areas are gathered and reviewed in terms of impact on the drivers of the business, a budget forecast can be frequently and easily refreshed, as well as be fully linked to the underlying assumptions [15].

However a review of driver-based planning would not be complete without acknowledging the drawbacks and limitations to this approach. One of the most significant obstacles to driver-based planning is the difficulty in indentifying the correct operational drivers and understanding the underlying assumptions associated with these drivers. This is critical to achieve a successful rolling forecast [16]. The following section will explore the manner in which business intelligence (BI) processes, techniques, and methodologies can help identify the appropriate drivers, predictability measures, and performance evaluators.

\section{Using Business Intelligence to Understand Key Drivers}

Driver-based planning allows managerial decisions to be based on the rigorous testing of business assumptions to gauge the feasibility of specific operational plans. This allows for organizations to make better use of its resources to achieve its financial and strategic targets [19]. The key to this approach is effectively utilizing the vast quantity of data at the department and organizational level, as well as understanding essential organizational information. Business intelligence approaches, methodologies, and tools provide the foundation of this approach [19].

The term business intelligence is defined as the purposeful use of data in order to make decisions, build value, and further the strategic goals of an organization, its units, and its employees. Business intelligence involves the application of diverse data analysis tools, methodologies, and processes in order to identify and understand the business context that allows an organization to achieve its targeted goals [19].

The strategic use of business intelligence can be ap- plied to the vast amount of information found in corporate databases, which can directly support a robust and flexible driver-based rolling forecast and provide greater value for an organization [8]. The next section will build on this definition by exploring an expanded concept of business intelligence using a comprehensive framework that includes information technology, statistics, and operations research/management science [20].

\subsection{An Expanded View of Business Intelligence to Support Driver-Based Forecasting}

Implementing and supporting driver-based forecasting requires an understanding of the relationship and interdependence between business information intelligence, statistical intelligence, and business modeling intelligence. These three key areas comprise the underlying foundation of an organization's business intelligence architecture and are vital to the support of driver-based rolling forecasts [20].

For example, technological advances in data warehousing and data marts allow for the collection and storage of large volumes of data that had formerly been housed in business silos, either in spreadsheets or source transactional systems. The ability to retrieve data from multiple source systems and store everything in one integrated data warehouse or data mart allows financial planners to access data that was formerly locked away [15].

When used with data integration and information deployment, forecasting becomes even more powerful when based on multiple data sources and disseminates forecast results consistently [4]. Accessibility to data from diverse functional areas, such as sales, production, and accounting, enables a financial analyst to have insight into how the business is actually performing, and subsequently, the ability to mine and analyze those data to identify and understand key drivers of the business [7].

However, organizational data can be so voluminous that it can be overwhelming and enigmatic, creating significant obstacles for identifying key business drivers. In fact, the task of extrapolating, cleansing, and integrating organizational data often impedes the time required to actually analyze and report the findings [21]. This hurdle can be overcome with the use of data mining techniques and statistical analyses. Data mining approaches allow managers to gain better visibility into what fundamentally drives the business, as well as discern any hidden patterns and trends that may provide insight. Examples of these statistical techniques include multiple regression, factor analysis, and analysis of variance [23].

\subsection{Additional Business Intelligence Approaches for Driver-Based Planning}

Data visualization tools and techniques can also shed 
light on trends, highlight interdependences, test data relationships, and reveal factors that may impact key business drivers that previously were hidden [22]. Sophisticated statistical software, now readily available and functional for all levels of analyst expertise, allows organizations to easily conduct various analyses on large quantities of data in order to provide the intelligence relating to underlying business drivers, previously out of reach of line managers and those involved with organizational financial planning [21].

In order to further efforts, performance management software is readily available and allows managers to effectively and efficiently prepare reports, communicate findings, and influence those in key functional areas regarding significant findings and outcome of the analysis, particularly key drivers for the organization [7]. As a result, the respective key drivers are then used to implement and maintain rolling forecasts in order to better align operational activities to the strategic direction of the organization [3].

However, a discussion on the topic of key organizational drivers and the manner in which they are used to align operational execution to strategic direction would not be complete without how these activities factor into a competitive advantage and add to shareholder value. The following section explores this topic and expands the framework of driver-based rolling forecasts.

\section{Driver-Based Planning and Value Creation}

A well-executed business intelligence strategy contributes to gaining insight into better time and resource allocation, improved business processes, and the ability to mitigate risks while leveraging opportunities. With this kind of insight, a business can select the critical business drivers at each organizational level that maximizes a positive economic value, which is often measured in terms of shareholder return [14]. The following sections explore this concept more fully and explain the manner in which the implementation of driver-based planning can link business operations vertically and horizontally. This linkage helps connect the business operations to the overall strategic direction of a business and often creates improved efficiencies, which in turn maximizes economic value for the organization and its shareholders [12].

\subsection{Value Drivers}

A crucial outcome of basing financial forecasts on operational drivers is often the improved support of an organization's performance management goals, as well as the creation of shareholder value [24]. One way to conceptualize this notion of value creation is to understand the manner in which diverse functional areas of a business are interrelated and are operationally aligned to drive this economic value [14].

However, the concept of value creation is rooted in the prerequisite that value is something that is embedded in the strategy of the organization and actively implemented within the business plan. In other words, value doesn't simply happen by chance [24]. This notion is directly related to the concept of driver-based forecasting and is illustrated in such approaches as enterprise resource planning and value mapping [25].

Value mapping addresses the manner in which value is created within an organization. For example, business volume and price realization can be identified as value drivers for company revenue. Using this approach, driver-based forecasting is applied to these variables as volume $\times$ price $=$ revenue. However underlying price variables, such as price optimization, demand, and supply management are considered when using the value mapping approach. For example, when examining the price optimization variable, optimized pricing can be achieved through the analysis of the costs and subsequent markups that drive price [27].

The analysis of costs and markups is best achieved through the development of data warehouses and statistical analysis to arrive at optimal price [27]. This illustrates the ability for business intelligence to create economic value through driver-based forecasting relationships, such as optimal price and increased sales [25].

\subsection{Key Actions to Drive Value}

Improvement levers are often defined as organizational activities that facilitate the planning, implementation, and control of targeted departmental and organizational goals [13]. Value mapping facilitates the identification of such improvement levers and enables managers to understand the relationship between business processes, corporate assets, and organizational capabilities, as well as the manner in which these areas contribute to achieving short-term and long-term objectives. Improvement levers apply to all functional areas and business disciplines and each area has multiple options to the manner in which it creates economic value [27].

For example, new customer acquisition can be identified as an improvement lever for a number of functional areas within an organization. By implementing driverbased planning, business intelligence capabilities can be utilized to identify the key drivers that help an organization make changes and improvements to customary business practices [27].

This is key when using value mapping to implement driver-based planning. Not only does it involve making improvements to business processes and organizational 
capabilities through the use of business intelligence methodologies, it also involves understanding the systemic organizational changes that are needed to maximize shareholder value [10].

For example, value mapping seeks to understand how an organization can improve its products, the manner in which it allocates resources, and the most appropriate target market. In utilizing data from transactional systems that support sales, billing, marketing, capital asset management, supply chain management, and other areas, key insight into what drives the business can be identified [27].

\subsection{Business Intelligence and Shareholder Value}

Through the use of data warehousing and statistical analyses, organizations can analyze which services and products add value, which do not, and how they interrelate. Businesses can analyze marketing campaigns to see which are most effective, as well as determine the impact of the marketing campaigns on sales and revenue [25]. Through these analyses, a sales-from-marketing driver can be developed, which directly links marketing to sales. As a result, sales and revenue are now linked directly to shareholder value, a strategic target [27].

This sales-from-marketing driver then serves to evaluate the impact of potential changes through driver-based forecasting. It measures the change in shareholder value and is used to select from various value-creation alternatives. This step is repeated among, between, and across business disciplines using robust business intelligence technologies [24]. This approach employs business intelligence from the strategic context of the business manager, rather than a technological context [8].

Improvements to processes in order to align organizational strategies with corporate resources is another key step in the value mapping proposition, as well as create economic value for the organization and its shareholders [27]. Predictive modeling, using "what-if” scenarios, is an important facet to this approach as it relates to understanding the manner in which key business drivers will affect operational and business outcomes [16]. Value mapping addresses this component and works to directly align resources with strategies [27].This is another clear benefit of business intelligence driver-based rolling forecasting and the manner in which it supports the creation of value.

\section{Conclusions}

Traditional, fixed budgeting has a long history. It is often treated as an obligatory annual event, the means by which senior management attempts to achieve organizational objectives while containing expenses and assessing management performance. However, this process is fraught with deficiencies. Static and outdated almost before the ink dries, the traditional, fixed budget creates a command-and-control environment that drives planners and managerial decision-makers to work around the system, rather than using a comprehensive tool that is aligned with an organization's strategic direction.

However, replacing the annual budget with business intelligence driver-based rolling forecasts offers an improved approach. The strengths of this approach lies in the following three key areas: 1) its adherence to datadriven management, 2) the utilization of non-static financial techniques that are much more dynamic and responsive to a changing business environment, and 3) the exploitation of business intelligence methods. When technology, data, and analytics are leveraged to plan for the future and react to changing business climates, an organization can achieve better economic results for their customers, employees, and shareholders. Driver-based planning allows for better insight into controllable revenue and expense items and allows for greater flexibility in responding to uncertainty. Of course, there are challenges to this approach. For example, management buy-in is required and there may be resistance to this method, especially for those organizations that do not have expertise or experience in this area. As a result, further exploration and research is encouraged in this area.

Driver-based rolling forecasts also allow for "what-if" scenario analysis so that a business can evaluate many different action plans. This approach also links disparate operating units with the overall corporate strategy. Frequent and flexible re-forecasting provides management with better intelligence for decision making. More informed decisions, in turn, help create greater economic value.

\section{REFERENCES}

[1] P. S. Greenberg and R. H. Greenberg, "Who Needs Budgets? You Do,” Strategic Finance, Vol. 88, No. 2, 2006, pp. 41-45.

[2] T. Malkovic, "Death Knell for Fixed Budgets," Charter, Vol. 82, No. 3, 2011, pp. 40-43.

[3] F. Bartes, "Action Plan-Basis of Competitive Intelligence Activities,” Economics and Management, Vol. 16, 2011, pp. 664-669.

[4] R. L. Keeney and H. Raffia, "Decisions with Multiple Objectives: Preferences and Valuable Tradeoffs,” John Wiley, New York, 1976.

[5] D. A. Fulgham, "Budget-Making," Aviation Week \& Space Technology, Vol. 172, No. 29, 2010, p. 66.

[6] S. C. Hansen, "A Theoretical Analysis of the Impact of Adopting Rolling Budgets, Activity-Based Budgeting and Beyond Budgeting," European Accounting Review, Vol. 20, No. 2, 2011, pp. 289-319. doi:10.1080/09638180.2010.496260 
[7] A. A. Carmen and G. Corina, "A Strategic Approach of Management Accounting," Annals of the University of Oradea, Economic Science Series, Vol. 18. No. 3, 2009, pp. 736-741.

[8] B. G. Ekholm, "The Impact of Uncertainty and Strategy on the Perceive Usefulness of Fixed and Flexible Budgets,” Journal of Business Finance \& Accounting, Vol. 38, No. 1/2, 2011, pp. 145-162. doi:10.1111/j.1468-5957.2010.02228.x

[9] G. Veth, "Allocating Resources to Ensure Execution," DM Review, Vol. 16, No. 12, 2006, pp. 28-38.

[10] P. D. Kimmel, J. J. Weygandt and D. E. Kieso, “Accounting: Tools for Business Decision Makers,” 4th Edition, John Wiley \& Sons, Ltd., Hoboken, 2011.

[11] B. Bozeman and J. D. Straussman, "Shrinking Budgets and the Shrinkage of Budget Theory," Public Administration Review, Vol. 42, No. 6, 1982, pp. 509-515. doi:10.2307/976120

[12] L. Lang, "The Power of Information," Financial Executive, Vol. 15, No. 5, 1999, pp. 46-47.

[13] R. Heer, "Positive Outcome," AFP Exchange, Vol. 30, No. 8, 2010, pp. 52-54.

[14] G. Veth, "Driver-Based Planning: A Competitive Advantage, 2005.

http://www.b-eye-network.com/print/444

[15] M. D. Troutt, D. W. Gibbin, M. Shanker and A. Zhang, "Cost Efficiency Benchmarking for Operational Units with Multiple Cost Drivers,” Decision Sciences, Vol. 31, No. 4, 2000, pp. 813-832. doi:10.1111/j.1540-5915.2000.tb00944.x

[16] G. Veth, "Better Resource Allocation with Cause-andEffect Resource Analysis,” DM Review, Vol. 17, No. 1, 2007, pp. 37-38.

[17] K. Danvers and C. A. Brown, "Out-West Products, Inc: A Financial Modeling and Decision Analysis Case,” Journal of Accounting Education, Vol. 27, No. 1, 2009, pp. 40-57. doi:10.1016/j.jaccedu.2009.06.002
[18] R. Rohloff, "Healthcare BI: A Tool for Meaningful Analysis," Healthcare Financial Management, Vol. 65, No. 5, 2011, pp. 100-108.

[19] R. T. Herschel and N. E. Jones, "Knowledge Management and Business Intelligence: The Importance of Integration,” Journal of Knowledge Management, Vol. 9, No. 4, 2005, pp. 45-55. doi:10.1108/13673270510610323

[20] R. K. Klimberg and V. Miori, "Back in Business," OR/ MS Today, Vol. 37, No. 5, 2010, pp. 22-26.

[21] S. H. Hung, D. C. Yen and H. Y. Wang, “Applying Data Mining to Telecom Churn Management,” Expert Systems with Applications, Vol. 31, No. 3, 2006, pp. 515-524. doi:10.1016/j.eswa.2005.09.080

[22] M. Chen, D. Ebert, H. Hagen and R. S. Laramee, "Data, Information, and Knowledge in Visualization,” Computer Graphics and Animation, Vol. 29, No. 1, 2009, pp. 12-19.

[23] R. E. Duran, "Studies in Fuzziness and Soft Computing, Applications in Business,” Springer, New York, 2008.

[24] M. Ezzamel, H. Willmott and F. Worthington, "Manufacturing Shareholder Value: The Role of Accounting in Organizational Transformation,” Accounting, Organization, and Society, Vol. 33, No. 2/3, 2008, pp. 107-140. doi:10.1016/j.aos.2007.03.001

[25] P. Frow, A. Payne and M. Ezzamel, “A Stakeholder Perspective of the Value Proposition Concept," European Journal of Marketing, Vol. 45, No. 1/2, 2011, pp. 223240. doi:10.1108/03090561111095676

[26] M. Al-Mashari, M. Zairi and K. Okazawa, "Enterprise Resource Planning: A Useful Road Map,” International Journal of Management and Enterprise Development, Vol. 3, No. 1/2, 2006, pp. 169-180. doi:10.1504/IJMED.2006.008248

[27] Deloitte, Deloitte Enterprise Value Map, 2004. http://public.deloitte.com/media/0268/enterprise_value_m ap_2_0.pdf 